\title{
Posterior Tibial Slope and Medial Tibial Depth Measured by MRI in Patients with Posterior Cruciate Ligament Injury: A Case-Control Study
}

Aiguo Zhou ( $\square$ zhouaiguo@hospital.cqmu.edu.cn )

the First Affiliated Hospital of Chongqing Medical University

Baoshan Yin

the First Affiliated Hospital of Chongqing Medical University

Pei Zhao

the First Affiliated Hospital of Chongqing Medical University

Jiaxing Chen

the First Affiliated Hospital of Chongqing Medical University

Wenlong Yan

the First Affiliated Hospital of Chongqing Medical University

Hua Zhang

the First Affiliated Hospital of Chongqing Medical University

Jian Zhang

the First Affiliated Hospital of Chongqing Medical University

\section{Research Article}

Keywords: Magnetic resonance imaging, posterior cruciate ligament, posterior tibial slope

Posted Date: March 8th, 2022

DOI: https://doi.org/10.21203/rs.3.rs-1352758/v2

License: (-) (1) This work is licensed under a Creative Commons Attribution 4.0 International License. Read Full License 


\section{Abstract}

Objectives To 1) figure out the difference in tibial morphologies between patients with posterior cruciate ligament (PCL) injury and those without, 2) identify any tibial anatomical variations contributing to PCL rupture.

Design Retrospective case-control study, level of evidence III.

Methods 45 patients with PCL rupture from 2015 to 2020 in our hospital, and 45 patients matched by age and sex with intact PCL were enrolled in our study. The intraclass correlation coefficient (ICC) was used to assess the reliability of each parameter. The independent t-test was conducted to identify the differences in tibial morphometric characteristics between the PCL-injured and PCL-intact individuals, including the posterior tibial slope (PTS), meniscal slope (MS), medial tibial depth (MTD). A binary logistic regression model was established to evaluate the roles of those anatomic parameters of interest play in PCL injuries.

Results The interobserver reliability of each parameter showed excellent agreement. Significant differences in the medial $(P=.023)$ and lateral $(P=.009)$ PTS were found between the PCL-injured group ( $3.68 \pm 2.70$ and $4.55 \pm 3.19$, respectively) and the controls $(5.00 \pm 2.73$ and $6.39 \pm 3.29$, respectively). And the MTD was $1.98 \pm$ $0.64 \mathrm{~mm}$ in the PCL-injured group and $2.37 \pm 0.55 \mathrm{~mm}$ in the control group $(P=0.007)$. Binary logistic regression analysis showed that smaller lateral PTS and MTD were directly associated with PCL injury, with an OR of 1.17 and OR of 3.14, respectively. The medial PTS was independent to PCL injures.

Conclusion In patients with PCL injury, lateral PTS, medial PTS, and MTD were found smaller compared to PCL intact controls. Decreased lateral PTS and MTD were underlying anatomic risk factors for PCL injury, with each unit reduction, the risks of PCL injury were 1.2 and 3.1-fold higher, respectively.

\section{Background}

The main function of the posterior cruciate ligament $(\mathrm{PCL})$ is to restrict the excessive posterior movement of the tibia relative to the femur, maintaining the posterior stability of knee joint ${ }^{1}$. PCL injury always combined with other injuries, such as medial collateral ligaments, anterior cruciate ligament (ACL), or chondral injuries, especially in the lateral tibiofemoral compartment ${ }^{2}$, which would cause instability, accelerating degeneration of the knee joint. It was accepted that femorotibial biomechanics were influenced by the morphology of the tibial plateau and femoral condyles ${ }^{3}$. Biomechanically, excessive posterior tibial slope (PTS) was considered as a predisposing risk factor for ACL noncontact injury, because of its contribution to the increase of tensity for native ACL, particularly in axial compressive forces condition. In contrast, the stress on PCL would increase with smaller PTS.

As an adjunctive examination that can effectively detect cruciate ligament injury, measurements on MRI were valued by clinicians and researchers. For non-contact injuries of the ACL, recent research has identified the risk factors, such as the excessive bony posterior tibial slope (PTS), the shallow medial tibial plateau ${ }^{4-6}$, and the femoral inter-condylar fossa stenosis ${ }^{78}$. Biomechanical studies have shown that excessive bony PTS can increase the tension on ACL, but the soft tissue (cartilage and meniscus) has a compensatory effect on the abnormality of bony structures. Moreover, shallow medial tibial plateau depression (MTD) reduced the 
limitation of relative motion of the femur over the tibia during closed chain movements ${ }^{910}$. Similarly, anatomic abnormalities at the proximal tibia also have an impact on the PCL, the lesser PTS, the more tension the PCL suffered ${ }^{11}$.

Fully understanding the impact of the proximal tibial morphology on PCL is important to guide the treatment and postoperative rehabilitation exercise of patients. However, such a study is lacking in clinical practice. Bony PTS in PCL injured knees measured on lateral radiographs was decreased compared with controls, and Giffin

et al. ${ }^{12}$ determined that increased PTS in PCL ruptured knees shifted the resting position of the tibia relative to the femur anteriorly. On the other hand, little information is available regarding tibial plateau anatomy measuring on magnetic resonance imaging $(\mathrm{MRI})$ in patients with PCL rupture ${ }^{13} 14$.

Due to the insufficient knowledge in the literature, the principal aim of this study was to figure out the difference in tibial morphologies between patients with PCL injury and those without, and to identify any variations contributing to PCL rupture.

\section{Materials And Methods}

\section{Study population}

Approval from the hospital ethics committee was obtained before this study started (IRB Number: 2021-038). 71 patients with PCL injury, identified in the Medical Record Registration System of our hospital from January 2015 to December 2020, were eligible for inclusion of this study. The inclusion criteria were subjects with an MRI scan in the picture archiving and communication system (PACS); the PCL rupture was identified by arthroscopy. Subjects with previous osteotomy or fracture, meniscal repair, or partial meniscectomy, which would influence the measurement of PTS and/or meniscal slope (MS); subjects with PCL avulsion fractures or ACL injuries; subjects with discoid meniscus were excluded from this study. Among the 71 patients, 16 patients with ACL injury, five patients with PCL avulsion fractures, three patients with severe menisci injury (Bucket Handle Tear) that can affect the accuracy of the MS, one patient with previous ACL reconstruction, one patient with lateral discoid meniscus were excluded from this study.

As a result, 45 patients with PCL rupture were included in the study. Among them, some concomitant injuries were presented and included partial meniscus rupture, cartilage injury, bone marrow edema, but those could not influence the accuracy of the measurements. The PCL-intact control group, matched by age and sex was built to include 45 individuals who came to the radiology department of our hospital for knee-MRI-scanning only with anterior knee pain and without a history of knee injury. And the MRI of each individual was retrospectively reviewed by two experienced orthopedists to ensure the participants' eligibility for the study. The informed consent requirement was waived by the Institutional Review Board of the First Affiliated Hospital of Chongqing Medical University.

\section{MRI Technique}

The MRI examinations were performed within one week prior to surgical planning in patients with PCL injuries. All examinations were performed with the same 1.5T MRI scanner (Siemens Magnetom Essenza, Germany). 
The coronal and sagittal planes were scanned with the T1-weighted turbo spin-echo (TSE) sequence and proton density (PD) TSE with the fat-suppressed (FS) sequence, and the axial plane was scanned with the PDTSE-FS. The layer thickness was set to $3 \mathrm{~mm}$, the slice gap was $0.5 \mathrm{~mm}$, the field of view (FOV) was $160 \mathrm{~mm}$, and the matrix size was $512 \times 512$.

\section{Measurements}

Anatomic parameters were obtained on MRI by two observers in a blinded and randomized fashion through PACS workstation to determine inter-observer reliability. Both observers were trained in consensus in the measuring methods. The values measured by the 2 observers were averaged for the statistical analysis.

The literature suggested that separate assessment of the PTS was not reliably possible on lateral radiographs, the reliable and reproducible methods conducted on MRI or computed tomography (CT) images were recommended to measure the PTS ${ }^{6}$. It varies in the literature regarding the definition of the lateral tibial axis on MRI ${ }^{15-17}$, we conducted the method described by Hudek et al. ${ }^{17}$, which was reported to be the most repeatable and reliable method to measure sagittal tibial slopes on MRI ${ }^{15} \llbracket a$ T1-weighted mid-sagittal cut was selected with the appearance of PCL-tibial insertion point, the tibial axis was defined as the line through both center of circles drawing on the sagittal image, and tibial axis was used to measure the medial and lateral PTS (Fig. 1) and MS (Fig. 2) on the other two sagittal images (the mid-medial tibial plateau cut and the mid-lateral tibial plateau cut), respectively.

MTD is the depth of concavity of the medial plateau in the middle of the articular region. The perpendicular distance between the line connecting the uppermost superior-anterior and posterior cortex edges of the medial tibial plateau, and the lowest point of the medial plateau concavity ${ }^{18}$. (Fig. 3)

\section{Statistical analysis}

The average values of the variables measured by both observers were used for all analyses. The Independent t-test was conducted to compare the parameters between the two subgroups, and binary logistic regression analysis was used to determine the probability of PCL injury in an individual based on the measured covariates. All analysis was conducted by a coauthor independently via the SPSS software (Version 22.0; IBM Corp), and the $\mathrm{P}$ value of $<0.05$ was considered statistic significant. The interclass correlation coefficient (ICC) was calculated to assess the reliability of each parameter, with a value of more than 0.75 indicating excellent agreement.

G*Power 3.1 (Heinrich-Heine-Universitat Dusseldorf, Dusseldorf, Germany) was used to perform power analysis. Regarding the difference in the lateral PTS between the two groups, for a large effect size (0.56), the results indicated that at least 40 patients were needed in this study (alpha, 0.05 ; power, 0.8 ).

\section{Results}


The study, as a result, included 45 patients with PCL injuries, with a mean \pm standard deviation (SD) age of $43.4 \pm 11.8$ years, and 45 age and sex matched individuals (age of $42.7 \pm 10.2$ ) with intact PCL. The interval time between injury and MRI examination in PCL injured group was $4.2 \pm 2.5$ days. The descriptive data of both groups is presented in Table 1.

Table 1

Demographic data of the two groups.

\begin{tabular}{|llll|}
\hline & $\begin{array}{l}\text { PCL injured } \\
(\mathbf{n = 4 5 )}\end{array}$ & $\begin{array}{l}\text { Controls } \\
(\mathbf{n = 4 5 )}\end{array}$ & P value \\
\hline Age, yr & $43.4 \pm 11.8$ & $40.7 \pm 7.2$ & n.s \\
\hline Sex, (female/male) & $17 / 33$ & $20 / 30$ & n.s \\
\hline Side, (left/right) & $20 / 30$ & $23 / 27$ & n.s \\
\hline BMl, kg/m² & $25.8 \pm 2.1$ & $24.9 \pm 2.8$ & \\
\hline Interval time, day & $4.2 \pm 2.5$ & & \\
\hline $\begin{array}{l}\text { PCL, posterior cruciate ligament; BMl, body mass index; Interval time, the mean time between injury and } \\
\text { MRI examination. }\end{array}$ & & \\
\hline
\end{tabular}

The interobserver reliability of each parameter both in the PCL injured group and control group showed excellent agreement, the ICC of each measurement was more than 0.75 (Table 2). The results of the independent t-test for comparison of the variables between the two groups were presented in Table 3 . Significant differences in the medial $(P=.023)$ and lateral $(P=.009)$ PTS were found between the study group (3.68 \pm 2.70 and $4.55 \pm 3.19$, respectively) and the control group (5.00 \pm 2.73 and $6.39 \pm 3.29$, respectively). The MTD was $1.98 \pm 0.64 \mathrm{~mm}$ in the PCL-injured group and $2.37 \pm 0.55 \mathrm{~mm}$ in the control group $(P=0.007)$. Both medial MS and lateral MS were smaller in the PCL-injured group than those in the control group, but the differences did not show statistical significance $(p=n . s$.). 
Table 2

Inter-observer reliability analysis and mean \pm SD of PTS, MS, MTD in two subgroups.

\begin{tabular}{|c|c|c|c|c|c|c|c|c|}
\hline \multirow[t]{2}{*}{ Variables } & \multicolumn{4}{|c|}{ PCL ruptures group } & \multicolumn{4}{|c|}{ Control group } \\
\hline & Observer1 & Observer2 & Average & $\begin{array}{l}\text { ICC } \\
(95 \% \\
\mathrm{Cl})\end{array}$ & Observer1 & Observer2 & Average & $\begin{array}{l}\text { ICC } \\
(95 \% \\
\text { Cl) }\end{array}$ \\
\hline \multicolumn{9}{|l|}{ PTS } \\
\hline \multirow{2}{*}{$\begin{array}{l}\text { Lateral } \\
\text { PTS }\end{array}$} & \multirow{2}{*}{$\begin{array}{l}4.53 \pm \\
3.36\end{array}$} & \multirow{2}{*}{$\begin{array}{l}4.58 \pm \\
3.06\end{array}$} & \multirow{2}{*}{$\begin{array}{l}4.55 \pm \\
3.19\end{array}$} & 0.985 & \multirow{2}{*}{$\begin{array}{l}6.52 \pm \\
3.44\end{array}$} & \multirow{2}{*}{$\begin{array}{l}6.26 \pm \\
3.24\end{array}$} & \multirow{2}{*}{$\begin{array}{l}6.39 \pm \\
3.29\end{array}$} & 0.968 \\
\hline & & & & $\begin{array}{l}(0.973 \\
0.992)\end{array}$ & & & & $\begin{array}{l}(0.942, \\
0.982)\end{array}$ \\
\hline \multirow{2}{*}{$\begin{array}{l}\text { Medial } \\
\text { PTS }\end{array}$} & \multirow{2}{*}{$\begin{array}{l}3.56 \pm \\
2.85\end{array}$} & \multirow{2}{*}{$\begin{array}{l}3.63 \pm \\
2.65\end{array}$} & \multirow{2}{*}{$\begin{array}{l}3.68 \pm \\
2.70\end{array}$} & 0.985 & \multirow{2}{*}{$\begin{array}{l}4.63 \pm \\
2.83\end{array}$} & \multirow{2}{*}{$\begin{array}{l}5.37 \pm \\
2.87\end{array}$} & \multirow{2}{*}{$\begin{array}{l}5.00 \pm \\
2.73\end{array}$} & 0.908 \\
\hline & & & & $\begin{array}{l}(0.972, \\
0.992)\end{array}$ & & & & $\begin{array}{l}(0.832, \\
0.949)\end{array}$ \\
\hline \multicolumn{9}{|l|}{ MS } \\
\hline \multirow{2}{*}{$\begin{array}{l}\text { Lateral } \\
\text { MS }\end{array}$} & \multirow{2}{*}{$\begin{array}{l}2.60 \pm \\
3.23\end{array}$} & \multirow{2}{*}{$\begin{array}{l}2.87 \pm \\
3.42\end{array}$} & \multirow{2}{*}{$\begin{array}{l}2.74 \pm \\
3.29\end{array}$} & 0.977 & \multirow{2}{*}{$\begin{array}{l}2.90 \pm \\
2.98\end{array}$} & \multirow{2}{*}{$\begin{array}{l}3.24 \pm \\
3.41\end{array}$} & \multirow{2}{*}{$\begin{array}{l}3.07 \pm \\
3.08\end{array}$} & 0.919 \\
\hline & & & & $\begin{array}{l}(0.957 \\
0.987)\end{array}$ & & & & $\begin{array}{l}(0.852, \\
0.955)\end{array}$ \\
\hline \multirow{2}{*}{$\begin{array}{l}\text { Medial } \\
\text { MS }\end{array}$} & \multirow{2}{*}{$\begin{array}{l}3.28 \pm \\
3.83\end{array}$} & \multirow{2}{*}{$\begin{array}{l}3.41 \pm \\
3.33\end{array}$} & \multirow{2}{*}{$\begin{array}{l}3.34 \pm \\
3.52\end{array}$} & 0.960 & \multirow[t]{2}{*}{$\begin{array}{l}3.99 \pm \\
2.90\end{array}$} & \multirow[t]{2}{*}{$\begin{array}{l}4.26 \pm \\
3.31\end{array}$} & \multirow{2}{*}{$\begin{array}{l}4.13 \pm \\
3.00\end{array}$} & 0.923 \\
\hline & & & & $\begin{array}{l}(0.926 \\
0.978)\end{array}$ & & & & $\begin{array}{l}(0.860 \\
0.958)\end{array}$ \\
\hline \multirow[t]{2}{*}{ MTD } & \multirow{2}{*}{$\begin{array}{l}2.00 \pm \\
0.62\end{array}$} & \multirow{2}{*}{$\begin{array}{l}1.96 \pm \\
0.69\end{array}$} & \multirow{2}{*}{$\begin{array}{l}1.98 \pm \\
0.64\end{array}$} & 0.924 & $2.31 \pm$ & $2.44 \pm$ & $2.37 \pm$ & 0.902 \\
\hline & & & & $\begin{array}{l}(0.861 \\
0.959)\end{array}$ & & & & $\begin{array}{l}(0.822, \\
0.946)\end{array}$ \\
\hline $\begin{array}{l}\text { PTS, pos } \\
\text { coefficien } \\
\text { excellent }\end{array}$ & $\begin{array}{l}\text { tibial slop } \\
\text { standard } \\
\text { ment. }\end{array}$ & MS, men & slope; & , medi & bial dept & C, intracla & $\begin{array}{l}\text { correlatio } \\
75 \text { indicat }\end{array}$ & \\
\hline
\end{tabular}


Table 3

Comparison of the variables between subgroups

\begin{tabular}{|llll|}
\hline Variables & PCL ruptures & Controls & P value \\
\hline PTS & & & \\
\hline Lateral PTS & $4.55(-0.3,11.54)$ & $6.39(0.1,13.17)$ & $0.009^{*}$ \\
\hline Medial PTS & $3.68(-3.10,9.88)$ & $5.00(-0.32,12.39)$ & $0.023^{*}$ \\
\hline MS & & & \\
\hline Lateral MS & $2.74(-5.72,11.53)$ & $3.07(-4.28,9.94)$ & 0.513 \\
\hline Medial MS & $3.34(-6.38,11.28)$ & $4.13(-2.15,11.10)$ & 0.193 \\
\hline MTD & $1.97(1.10,3.05)$ & $2.37(0.95,3.75)$ & $0.007^{*}$ \\
\hline PTS, posterior tibial slope; MS, meniscus slope; MTD, medial tibial depth. \\
\hline
\end{tabular}

Showing by the results of Binary logistic regression analysis (Table 4), as eliminating other parameters from the regression model (simple analysis), lateral PTS and medial PTS revealed a significant OR of $1.19(95 \% \mathrm{Cl}$ $[1.04,1.37])$ and OR of $1.20(95 \% \mathrm{Cl}[1.11,1.42])$ with regard to PCL injury, respectively; the MTD was associated with PCL injury with an OR of 3.20 (95\% $\mathrm{Cl}[1.42,7.19])$; Medial MS was not considered as risk factors for PCL injuries $(P>.05)$. While the values of other parameters were considered constant (multivariable analysis), it was fond that except medial PTS, decreased lateral PTS and MTD were risk factors for PCL injury, with an OR of $1.17(95 \% \mathrm{Cl}[1.01,1.37])$ and $3.14(95 \% \mathrm{Cl}[1.28,7.73])$, respectively, indicating that for $1 \mathrm{~mm}$ decrease in MTD and 1 degree decrease in lateral PTS, the risk of PCL injury will increase 3.1 times and 1.2 times, respectively

Table 4

Binary logistic regression model of parameters of interest for PCL injury.

\begin{tabular}{|c|c|c|c|c|c|c|}
\hline Variables & Unadjusted ${ }^{a}$ & & & Adjus & & \\
\hline & OR & $95 \% \mathrm{Cl}$ & $P$ value & OR & $95 \% \mathrm{Cl}$ & $P$ value \\
\hline Lateral PTS & 1.19 & $1.04-1.37$ & $0.011^{*}$ & 1.17 & $1.01-1.37$ & $0.038^{*}$ \\
\hline Medial PTS & 1.20 & $1.11-1.42$ & $0.029 *$ & 1.20 & $0.95-1.52$ & 0.131 \\
\hline MTD & 3.20 & $1.42-7.19$ & $0.005^{\star}$ & 3.14 & $1.28-7.73$ & $0.013^{*}$ \\
\hline Medial MS & 1.09 & $0.95-1.25$ & 0.193 & 0.98 & $0.80-1.20$ & 0.838 \\
\hline
\end{tabular}




\section{Discussion}

The most inspiring findings of the present study were that both PTS and MTD were smaller in patients with $P C L$ injuries than those in controls, but the MS between the two groups was not statistically different. And except the medial PTS, the lateral PTS and MTD were considered underlying anatomic risk factors for PCL injury.

As for anatomic parameters in patients with PCL injury, recent literature ${ }^{13}$ proposed that PTS measured on lateral radiographs was decreased as compared with PCL-intact controls, but to the best of our knowledge, the medial and lateral PTS measured on MRI were unclear. As depicted by Bernhardson et al. ${ }^{19}$, PCL graft forces increased as a small tibial slope presented after PCL reconstruction. In addition, Gwinner et al. ${ }^{20}$ suggested that PTS could influence the stability of the knees, especially in patients with flattened PTS. In accordance with previous researches, the medial and lateral PTS were found smaller in patients with PCL-injures when compared to controls in this study. The difference in MS between subgroups in our study did not show statistical significance, indicating that soft tissue had some compensatory effect on bony PTS. Soft tissues (meniscus or cartilage) contributed to formulating a restriction of posterior direction motion on the knee joints. $3 / 71(4.2 \%)$ patients in this study were accompanied by severe menisci injury, which was an important manifestation of the loss of soft tissue restriction after PCL injury. It was unclear whether the front of the tibial plateau was thicker or the rear was thinner, further researches should focus on this issue.

On the other hand, there was a controversy in the literature whether the MS in patients with ACL injury was higher compared with controls. ${ }^{21-23}$ The concavity of medial tibial plateau was considered as a kind of stabilization of knee joints, and it was found decreased in patients with ACL injury ${ }^{5}$. In this study, the difference in MS between subgroups did not show statistical significance, and MTD was significantly decreased in patients with PCL injuries compared with controls, which was in accordance with previous studies related to the ACL injury 162122 .

We also identified that decreased lateral PTS and MTD were risk factors for PCL injury. It suggested that in patients with PCL injury, bony structures (PTS and MTD) played an important role in limiting the forward and backward movement of the tibia related to the femur in patients with PCL injuries. Shelburne et al. ${ }^{9}$ modeled cruciate force and found that increase in PTS decreased the native PCL force, noting an increase in PCL force when the slope was decreased. Patients with a normal tibial slope or increased tibial slope may require larger force at the time of injury to overcome the protective effect of posterior tibial slope on PCL injuries. Patients with decreased PTS could suffer from increased stress on the PCL, making it more prone to PCL injury with lesser violence.

Medial PTS was significantly decreased in patients with PCL injury compared with PCL intact controls, but it was found not a risk factor for PCL injury. The medial tibial plateau mainly affects the stability of the knee joint in the anteroposterior direction, while the lateral tibial plateau is mainly related to the stability of the knee joint rotation. This may indicate that PCL injury is closely related to the knee joint rotation instability, which needs to be confirmed by further studies. On the other hand, shallower MTD could contribute to PCL injury. The backward movement of the tibia related to the femur would be greater in patients with a shallow medial tibial plateau. 
The result of this study may to some extend be helpful in rehabilitation after PCL reconstruction: it should be more conservative in terms of weight-bearing after PCLR in patients with shallow MTD and/or small lateral PTS angle, due to the tibia is more prone to backward movement relative to the femur. If the radical functional rehabilitation is carried out, the risk of the grafts loosening and rupture may be increased. In contrast, whether radical functional rehabilitation is appropriate in patients with larger MTD and/or shaft lateral PTS. The cutoff values of lateral and medial PTS and MTD were unclear.

We acknowledged some limitations to this study. Injury mechanisms (contact and non-contact) and concomitant injuries (medial or fibular collateral ligaments) are not included in the analysis, which may influence the importance of the tibial slope and depth. Some femoral or tibial anatomic parameters are not included in this study, such as lateral femoral condyle ratio ${ }^{24}$, the shape of femoral notch 25 , lateral tibial plateau height. Further research, including femoral morphology is warranted. Notwithstanding these deficiencies, the study has addressed the gap in understanding tibial morphology in patients with PCL injury, and identifies the underlying risk factors for PCL injury. Future researches on anatomic parameters of femoral condyle are required in patients with PCL ruptures.

\section{Conclusion}

In patients with PCL injury, lateral PTS, medial PTS, and MTD were found smaller compared to PCL intact controls. Decreased lateral PTS and MTD were underlying anatomic risk factors for PCL injury, with each unit reduction, the risks of PCL injury were 1.2 and 3.1-fold higher, respectively.

\section{Abbreviations}

PCL: posterior cruciate ligament; ICC: intraclass correlation coefficient; PTS: posterior tibial slope; MS: meniscal slope; MTD: medial tibial depth; ACL: anterior cruciate ligament; MRI:magnetic resonance imaging; PACS: picture archiving and communication system; TSE: turbo spin-echo; PD: proton density; FS: fatsuppressed; FOV: the field of view; CT: computed tomography.

\section{Declarations}

\section{Ethics approval and consent to participate:}

The study was approved by the Ethics Committee of the First Affiliated Hospital of Chongqing Medical University (IRB Number: 2021-038). Research involving human participants, human material, or human data have been performed in accordance with the Declaration of Helsinki. We confirm that all methods were performed in accordance with the relevant guidelines and regulations.

\section{Consent for publication》}

Patients and the public are not involved in the design and conduction of this study. 


\section{Availability of data and materials:}

The datasets analysed during the current study are not publicly available due to ethical restrictions, but are available from Aiguo Zhou on reasonable request at zhouaiguo@hospital.cqmu.edu.cn.

\section{Competing Interest:}

None declared.

\section{Funding:}

This research received no specific grant from any funding agency in the public, commercial or not-for-profit sectors.

\section{Authors' contributions:}

All authors contributed to the study conception and design. Material preparation, data collection and analysis were performed by Baoshan Yin,Pei Zhao and Wenlong Yan. The first draft of the manuscript was written by Baoshan Yin, and modified by Jiaxing Chen, Pei Zhao and Aiguo Zhou. Hua Zhang and Aiguo Zhou retrospectively verify the patients with PCL injury and those with intact PCL. Jian Zhang provided theoretical supports. All authors commented on previous versions of the manuscript. All authors read and approved the final manuscript.

\section{Patient consent for publication:}

Not applicable.

\section{Acknowledgements:}

None.

\section{References}

1. DePhillipo NN, Cinque ME, Godin JA, et al. Posterior Tibial Translation Measurements on Magnetic Resonance Imaging Improve Diagnostic Sensitivity for Chronic Posterior Cruciate Ligament Injuries and Graft Tears. Am J Sports Med 2018;46:341-347.

2. Logan CA, Beaulieu-Jones BR, Sanchez G, et al. Posterior Cruciate Ligament Injuries of the Knee at the National Football League Combine: An Imaging and Epidemiology Study. Arthroscopy 2018;34:681-686.

3. Freeman MA, Pinskerova V. The movement of the normal tibio-femoral joint. J Biomech 2005;38:197-208. 
4. Feucht MJ, Mauro CS, Brucker PU, et al. The role of the tibial slope in sustaining and treating anterior cruciate ligament injuries. Knee Surg Sports Traumatol Arthrosc 2013;21:134-145.

5. Hashemi J, Chandrashekar N, Mansouri H, et al. Shallow medial tibial plateau and steep medial and lateral tibial slopes: new risk factors for anterior cruciate ligament injuries. Am J Sports Med 2010;38:5462.

6. Utzschneider S, Goettinger M, Weber P, et al. Development and validation of a new method for the radiologic measurement of the tibial slope. Knee Surg Sports Traumatol Arthrosc 2011;19:1643-1648.

7. Al-Saeed O, Brown M, Athyal R, et al. Association of femoral intercondylar notch morphology, width index and the risk of anterior cruciate ligament injury. Knee Surg Sports Traumatol Arthrosc 2013;21:678-682.

8. Bouras T, Fennema P, Burke S, et al. Stenotic intercondylar notch type is correlated with anterior cruciate ligament injury in female patients using magnetic resonance imaging. Knee Surg Sports Traumatol Arthrosc 2018;26:1252-1257.

9. Shelburne KB, Kim HJ, Sterett WI, et al. Effect of posterior tibial slope on knee biomechanics during functional activity. J Orthop Res 2011;29:223-231.

10. Hohmann E, Bryant A, Reaburn P, Tetsworth $\mathrm{K}$ Is there a correlation between posterior tibial slope and noncontact anterior cruciate ligament injuries? Knee Surg Sports Traumatol Arthrosc 2011;19 Suppl 1:S109114.

11. Agneskirchner JD, Hurschler C, Stukenborg-Colsman C, et al. Effect of high tibial flexion osteotomy on cartilage pressure and joint kinematics: a biomechanical study in human cadaveric knees. Arch Orthop Trauma Surg 2004;124:575-584.

12. Giffin JR, Stabile KJ, Zantop T, et al. Importance of tibial slope for stability of the posterior cruciate ligament deficient knee. Am J Sports Med 2007;35:1443-1449.

13. Bernhardson AS, DePhillipo NN, Daney BT, et al. Posterior Tibial Slope and Risk of Posterior Cruciate Ligament Injury. Am J Sports Med 2019;47:312-317.

14. van Kuijk KSR, Reijman M, Bierma-Zeinstra SMA, et al. Posterior cruciate ligament injury is influenced by intercondylar shape and size of tibial eminence. Bone Joint J 2019;101-b:1058-1062.

15. Lipps DB, Wilson AM, Ashton-Miller JA, et al. Evaluation of different methods for measuring lateral tibial slope using magnetic resonance imaging. Am J Sports Med 2012;40:2731-2736.

16. Li K, Li J, Zheng X, et al. Increased lateral meniscal slope is associated with greater incidence of lateral bone contusions in noncontact ACL injury. Knee Surg Sports Traumatol Arthrosc 2020;28:2000-2008.

17. Hudek R, Schmutz S, Regenfelder F, et al. Novel measurement technique of the tibial slope on conventional MRI. Clin Orthop Relat Res 2009;467:2066-2072.

18. Okazaki Y, Furumatsu T, Kodama Y, et al. Steep posterior slope and shallow concave shape of the medial tibial plateau are risk factors for medial meniscus posterior root tears. Knee Surg Sports Traumatol Arthrosc 2021; 29(1):44-50.

19. Bernhardson AS, Aman ZS, DePhillipo NN, et al. Tibial Slope and Its Effect on Graft Force in Posterior Cruciate Ligament Reconstructions. Am J Sports Med 2019;47:1168-1174.

20. Gwinner C, Weiler A, Roider M, et al. Tibial Slope Strongly Influences Knee Stability After Posterior Cruciate Ligament Reconstruction: A Prospective 5- to 15-Year Follow-up. Am J Sports Med 2017;45:355-361. 
21. Elmansori A, Lording T, Dumas $R$, et al. Proximal tibial bony and meniscal slopes are higher in ACL injured subjects than controls: a comparative MRI study. Knee Surg Sports Traumatol Arthrosc 2017;25:15981605.

22. Lustig S, Scholes CJ, Leo SP, et al. Influence of soft tissues on the proximal bony tibial slope measured with two-dimensional MRI. Knee Surg Sports Traumatol Arthrosc 2013;21:372-379.

23. Stijak L, Herzog RF, Schai P. Is there an influence of the tibial slope of the lateral condyle on the ACL lesion? A case-control study. Knee Surg Sports Traumatol Arthrosc 2008;16:112-117.

24. Pfeiffer TR, Burnham JM, Hughes JD, et al. An Increased Lateral Femoral Condyle Ratio Is a Risk Factor for Anterior Cruciate Ligament Injury. J Bone Joint Surg Am 2018;100:857-864.

25. van Eck CF, Martins CA, Vyas SM, et al. Femoral intercondylar notch shape and dimensions in ACL-injured patients. Knee Surg Sports Traumatol Arthrosc 2010;18:1257-1262.

\section{Figures}

\section{Figure 1}

Lateral and medial PTS. (A), sagittal MRI image shows the tibial attachment of the PCL and the intercondylar eminence. C1: circle 1 has to touch the anterior, posterior, and cranial tibial cortex bone C2: circle 2 has to touch the anterior and posterior cortex border. The longitudinal axis (LA) of the proximal tibia was defined by a line that connected the centers of these two circles. (B), sagittal MRI image shows the center of the medial tibial plateau, the LA is superimposed on the selected image. Line a: the line tangent to the medial plateau. Line $b$ : the line perpendicular to LA. The angle between line $a$ and line $b$ is defined as medial PTS. (C), sagittal MRI image shows the center of the lateral tibial plateau. Line $\mathrm{c}$ : the line tangent to the lateral plateau. Line d: the line perpendicular to LA. The angle between line $c$ and line $d$ is defined as lateral PTS.

\section{Figure 2}

Lateral and medial MS. (A), sagittal MRI image shows the anterior and posterior horns of lateral meniscus clearly. The LA is the longitudinal axis of the proximal tibia, line $f$ is perpendicular to LA, and line e joints the highest points of the anterior and posterior horns of lateral meniscus. The lateral MS is calculated as the angle between line e and line f. (B), sagittal MRI image shows the anterior and posterior horns of medial meniscus. Line $h$ is perpendicular to LA, and line $g$ joints the highest points of the anterior and posterior horns of medial meniscus. The medial MS is calculated as the angle between line $g$ and line $h$.

\section{Figure 3}


Medial tibial depth. Line i: the line tangent to the medial plateau, which is drawn to the proximal cortex border of the tibial plateau. Line $j$ gets through the lowest point of the medial concavity and parallel to line $i$. The distance between the two lines is defined as medial tibial depth (MTD). 